1 Department of Restorative Dentistry, School of Dentistry, Federal University of Juiz de Fora, UFJF, Juiz de Fora, Minas Gerais, Brazil.
Corresponding author: Department of Restorative Dentistry, School of Dentistry, Federal University of Juiz de Fora, UFJF, Juiz de Fora, MG, Brazil. Rua José Lourenço Kelmer, $\mathrm{S} / \mathrm{n}$ - São Pedro, Juiz de Fora - MG, $36036-900$. +55 (32) 98407-2427 luciana.salvio@ufjf.edu.br

Received: May 23, 2018

Accepted: December 09, 2018

\section{Effect of cavity-cleaning agents on shear bond strength between self-etching adhesives and dentin}

Tamiris Alacoque de Carvalho Freitas ${ }^{1}$, Bruno Salles Sotto-Maior ${ }^{1}$, Mariele Ferraz de Oliveira', Fabiana Cesar Costa ${ }^{1}$, Luciana Andrea Salvio ${ }^{1, *}$

Aim: The effect of cavity-cleaning agents on shear bonding strength between self-etching adhesives and dentin was evaluated. Methods: Twenty-five healthy human third molars were worn to obtain flat middle dentin. The samples were randomly divided into five groups according to the cleaning agent used: group CB not treated with any cavity disinfectants and served as control. Following groups, dentin surfaces were treated with $2 \%$ chlorhexidine ( $\mathrm{CHX}$ group); $3 \%$ hydrogen peroxide (HP group); calcium hydroxide water ( $\mathrm{CH}$ group); and $70 \%$ ethyl ethanol (E group). The dentin surfaces were cleaned by friction for $20 \mathrm{~s}$ and dentine bonding agent, Clearfil SE Bond, was applied. Cylinders ( $\left.5.0 \mathrm{~mm}^{\prime} 1.2 \mathrm{~mm}, \mathrm{n}=19\right)$ of fluid composite resin were placed on the dentin surface, and the teeth were stored in deionized water at $37^{\circ} \mathrm{C}$ for $24 \mathrm{~h}$. Subsequently, the samples were subjected to the shear bonding test, and the obtained values were subjected to one-way ANOVA and Tukey's test $(\alpha=0.05)$. The failure pattern was analyzed descriptively by examining the specimens with a stereoscope at a magnification of $4^{\prime}$, and failure was classified into adhesive, cohesive or mixed type. Results: Shear bonding was significantly lower in group HP $(6.17 \pm 5.69 \mathrm{MPa})$. The groups $\mathrm{CB}, \mathrm{CHX}, \mathrm{CH}$ and E were statiscally similar, $22.15 \pm 6.54 \mathrm{MPa} ; 18.40 \pm 7.26 \mathrm{MPa} ; 18.07 \pm 5.98 \mathrm{MPa}$; $16.43 \pm 6.19 \mathrm{MPa}$ respectively. The failure modes observed were only adhesive and mixed. Conclusion: The use of $2 \%$ chlorhexidine, calcium hydroxide water, and $70 \%$ ethyl ethanol did not negatively affect bond strength. Only $3 \%$ hydrogen peroxide is contraindicated as a cavity cleaner in adhesive restorative procedures when self-etching system is used.

Keywords: Chlorhexidine. Dental Bonding. Adhesives. 


\section{Introduction}

The integrity and longevity of restorative procedures using adhesive systems depend on several factors, including polymerization contraction, hydrolysis of the hybrid layer, and rate of penetration by bacteria, buccal fluids, and chemical substances and the presence of these factors can make the restoration last less than expected ${ }^{1-4}$.

During the cavity preparation, the dentin may be covered with bacteria, dirt, debris from diamond burs, and a smear layer, which may hinder the penetration of monomers during hybridization. The presence of some microorganisms are one of the main reasons for replacing restorations, and the toxins of these bacteria may diffuse through the dentinal tubules to the tooth pulp, causing sensitivity, pulp inflammation, and even necrosis ${ }^{1,5}$. Histological and bacteriological studies indicate that only a part of the dentin become sterile after cavity preparation, and the remaining bacteria may survive for more than one year ${ }^{6}$. However, Elkassas et al. ${ }^{1}$ found that bacteria might remain viable for 139 days in restorations performed under non-antiseptic conditions.

When the etch-and-rinse system is used, the phosphoric acid removes all the debris present in the dentin, making it ready to undergo hybridization, but this does not happen when self-etching systems are used, so a bactericides and bacteriostats substances are needed for clean up the dentin before restorative procedures. The use of this substances is questionable during clinical practice, because they may interfere in the quality of the bond strength created by the adhesive system ${ }^{7 \cdot 9}$. Therefore, the substances used for this purpose should maintain their antimicrobial action without affecting the bond strength of adhesive systems ${ }^{1}$.

For decades, many substances have been used as cavity-cleaning agents, including chlorhexidine digluconate, ethylene diamine tetra-acetic acid, sodium hypochlorite, hydrogen peroxide, iodine, benzalkonium chloride, copper sulfate, galardin, tetracycline, bisphosphonate, and quaternary ammonium compounds $5,6,10$. Therefore, the objective of this study is to evaluate the effect of cavity-cleaning agents on shear bonding strength between self-etching adhesives and human dentin immediate after restorative procedure and the hypothesis tested is that the use of these substances as cavity-cleaning does not influence the shear bonding strength when self-etching system is used.

\section{Materials and Methods}

The study was approved by the Human Research Ethics Committee of the Federal University of Juiz de Fora under Protocol No. 2.085.214. Twenty-five healthy human third molars were cleaned and stored in deionized water under refrigeration until use. The teeth were fixed in Teflon molds $(20 \mathrm{~mm} \times 25 \mathrm{~mm} \times 15 \mathrm{~mm}$ ) with self-curing acrylic resin (JET Clássico, Santa Catarina, Brazil), with the occlusal side facing down and a wax plate used as a guide plane on this side.

Subsequently, the occlusal enamel in the samples was worn off using a sanding machine (Politriz Lixadeira, Metalprisma, São Paulo, Brazil) with silicon carbide (SiC) discs at granulations $\# 80, \# 120$, and $\# 400$ to expose flat areas in the middle dentin, 
followed by granulation \#600 to standardize the smear layer. The samples were randomly distributed into five groups; $\mathrm{CB}$ (the control group); $\mathrm{CHX}$ (chlorhexidine); $\mathrm{HP}$ (3\% hydrogen peroxide); $\mathrm{CH}$ (calcium hydroxide water) and $\mathrm{E}$ (70\% ethyl ethanol) (Table 1).

All the substances tested were actively applied with a disposable brush tip for $20 \mathrm{sec}$ onds and dried using a mild air jet for 20 seconds before the application of the system adhesive. Hybridization was performed using the Clearfil SE Bond self-etching adhesive system (CB) (Kuraray, Tokyo, Okayama, Japan), as per the manufacturer's instructions. First the acid primer was applied actively for 20 seconds, dried with a mild air jet for 20 seconds followed by applying the adhesive actively for 20 seconds and drying with a light jet of air with subsequent light-cured with an LED lamp (Bluephase N- Ivoclar Vivadent, São Paulo, Brazil) at a light intensity of $1,200 \mathrm{~mW} / \mathrm{cm}^{2}$ for 20 seconds.

After hybridization, four cylinders of $5.0 \mathrm{~mm}$ ' $1.2 \mathrm{~mm}$ of fluid composite resin Z350 Filtek Flow (3M ESPE, St Paul, Minnesota, USA) were build up in each sample, using a polymer matrix, placed into the dentin and light-cured with an LED lamp (Bluephase $\mathrm{N}$ - Ivoclar Vivadent, São Paulo, Brazil) at a light intensity of $1,200 \mathrm{~mW} / \mathrm{cm}^{2}$ for $40 \mathrm{~s}$. All samples were stored in deionized water in a heater (Nova Ética, São Paulo, Brazil) at $37^{\circ} \mathrm{C}$ for 24 hours to obtain the maximum conversion of monomers into polymers of the adhesive bond systems and the composite resin used. The shear test was done after 24 hours, because it was expected to know if these cleaning protocol was efficient in self-etching systems immediate after restorative procedure simulating the clinical conditions.

The test specimens were subjected to the shear bonding test using a universal testing machine DL 2000, EMIC (São José dos Pinhais, Paraná, Brazil) coupled to a cell with a load of $500 \mathrm{kgf}$, where a $0.7-\mathrm{mm}$ orthodontic wire as a force actuator, at a speed of $1 \mathrm{~mm} /$ min until failure occurred (Fig. 1). The loads (in MPa) obtained in the shear

Table 1. Materials (manufactures) and composition of products used in the study

\begin{tabular}{lr}
\hline Material/ Manufacture & Composition \\
\hline $\begin{array}{l}\text { Clearfil SE Bond (Kuraray - } \\
\text { Okayama, Japan) }\end{array}$ & $\begin{array}{r}\text { 1-Primer: } 10-M D P, \text { HEMA, hydrophilic dimethacrylate, camphoroquinone, } \\
\text { N/N-diethanol p-toluidine and water }\end{array}$ \\
\hline $\begin{array}{l}\text { 2- Bond: 10-MDP, Bis-GMA, HEMA, camphoroquinone hydrophobic } \\
\text { dimethacrylate, } \\
\text { N/N-diethanol p-toluidine bond and coloidal silica }\end{array}$ \\
\hline $\begin{array}{l}\text { Filtek Z 350 XT Flow (3 M ESPE/ } \\
\text { St Paul, MN-USA) }\end{array}$ \\
$\begin{array}{l}\text { Silane-trated ceramic, Bis-GMA, Bis-EMA, TEGMA, silane-treated sílica, } \\
\text { silane-teated zircôniom oxide and functionalized dimethacrylate polymer }\end{array}$ \\
$\begin{array}{l}\text { Chlorhexidine 2\% (Maquira, } \\
\text { Maringá, Brazil) }\end{array}$ \\
$\begin{array}{l}\text { Calcium hydroxide PA } \\
\text { (Biodinâmica, lbiporã, Brazil) }\end{array}$ \\
$\begin{array}{l}\text { Hydrated ethanol 70 INPM } \\
\text { (Start, São Paulo, Brazil) }\end{array}$ \\
$\begin{array}{l}\text { Hydrogen peroxide at 10 volumes } \\
\text { (Farmax, Divinópolis, Brazil) }\end{array}$ \\
\hline
\end{tabular}




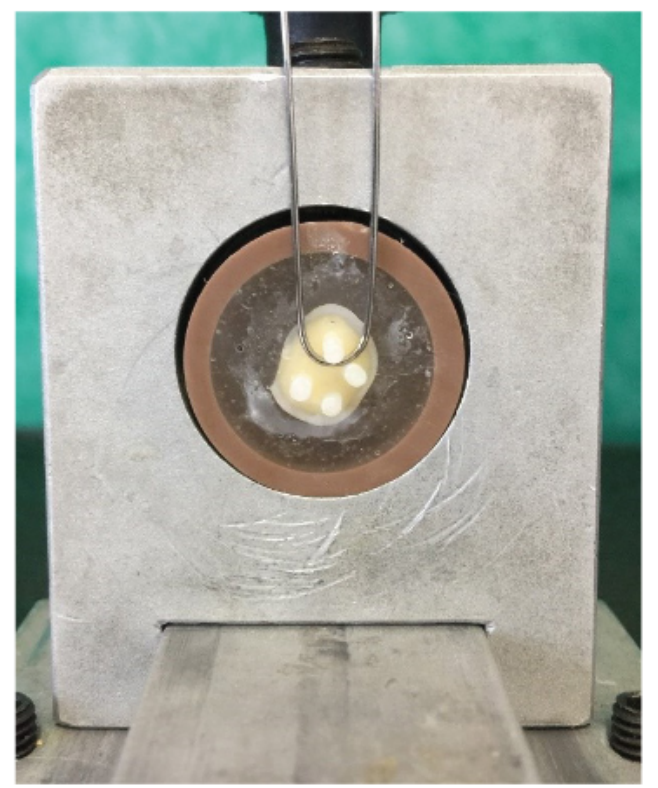

Figure 1. Sample placed on the Universal Testing Machine for the shear test.

Table 2. Shear bond strength values (standard deviation) according to the groups (MPa).

\begin{tabular}{lc}
\hline Groups & Mean \pm standard deviation $(\mathrm{MPa})$ \\
\hline Group CB & $22.15 \pm 6.54 \mathrm{~A}$ \\
\hline Group CX & $18.40 \pm 7.26 \mathrm{~A}$ \\
\hline Group HP & $6.17 \pm 5.69 \mathrm{~B}$ \\
\hline Group CH & $18.07 \pm 5.98 \mathrm{~A}$ \\
\hline Group E & $16.43 \pm 6.19 \mathrm{~A}$ \\
\hline
\end{tabular}

Different letters indicate significant difference between the treatment $(p<0.05)$

bonding test were analyzed using one-way analysis of variance (ANOVA) and Tukey tests at a level of significance of $5 \%(p \leq 0.05)$ by the IBM SPSS Statistics 21 Software.

The failure pattern was analyzed descriptively. The samples were examined under a stereomicroscope (SteREO Discovery Stereomicroscope, São Paulo, Brazil) coupled to a camera (AxionCam ERc5s, São Paulo, Brazil) at a magnification of $4 x$, and the failures were classified as adhesive (failure between dentin and restorative material), cohesive (failure in dentin or restorative material), or mixed (a combination of adhesive and cohesive failures).

\section{Results}

The obtained results are shown in Table 2. The statistical analysis indicated that applying chlorhexidine, calcium hydroxide water, and $70 \%$ ethyl ethanol did not decrease shear bonding strength and are also statistically similar, but 3\% hydrogen peroxide had significantly decreased. The results show that only adhesive and mixed failure occurred, being $63 \%$ adhesive failure and $37 \%$ mixed failure (figure 2). 


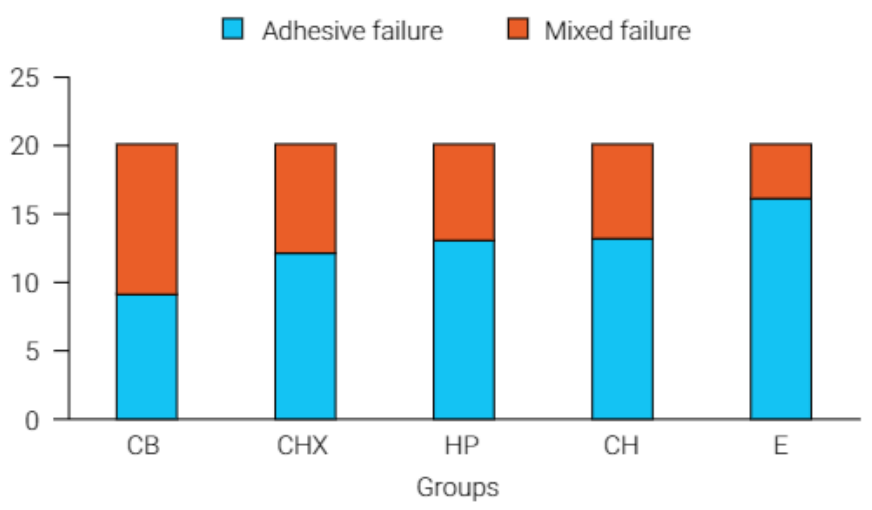

Figure 2. Distribution of failure modes.

\section{Discussion}

The hypothesis tested was rejected, since one of the substances tested, $3 \%$ hydrogen peroxide, presented statistically significant difference. The use of $3 \%$ hydrogen peroxide decreased shear bonding strength, probably because of the presence of oxygen at the dentin/adhesive interface, resulting in the formation of an oxygen inhibition layer and consequent inhibition of polymerization ${ }^{11}$. Similarly, Ercan et al. ${ }^{5}$ observed that $3 \%$ hydrogen peroxide in a self-etching adhesive system yielded lower failure load values, but the loads produced using a conventional adhesive system did not decrease.

The deterioration of the hybrid layer is primarily caused by the hydrolysis and leaching of the resinous monomers that infiltrated the demineralized dentin matrix ${ }^{12,13}$. Leaching is facilitated by the penetration of water into the crosslinked or hydrophilic domains of the adhesive. These domains have a limited rate of monomer-to-polymer conversion because of the separation of adhesive phases ${ }^{14}$ and the lack of compatibility between the hydrophobic photo initiator and the hydrophilic phase ${ }^{15}$. The poorly polymerized hydrophilic phase is degraded more rapidly in an aqueous medium $^{10}$. It is known that conventional adhesive and self-etching systems do not completely infiltrate the collagen network, and the fibrils that remain exposed become susceptible to degradation ${ }^{16}$.

Enzymes present in dentin, including MMPs and cathepsins, are responsible for the degradation of the hybrid layer and have been shown to be activated by acid conditioning ${ }^{17,18}$. To avoid these degradation, enzyme inhibitors can be used in different ways, for example, before or after the acid etching or incorporated in the adhesive system ${ }^{19}$.

The use of chlorhexidine in various concentrations is common in dental practice, and the use of this substance as a cavity-cleaning agent is part of the standard protocol in some countries. Chlorhexidine is effective against Gram-positive and Gram-negative bacteria and fungi as well as against the cathepsins MMPs 2, 8, and 920-23. The failure loads measured in this study in group $\mathrm{CHX}$, corroborate the results of previous studies $3,10,22$, where the use of this substance was shown to be acceptable because 
it does not significantly decrease shear bonding strength. When $\mathrm{CHX}$ is applied, an attack of moderately soluble phosphate crystals occurs, which, when not rinsed, may interfere in the bond quality due to the impedance of the monomer penetration into the dentin tubules ${ }^{24}$. In the present study, this precipitated phosphate crystals did not prevent the penetration of the monomers.

In low concentrations, $\mathrm{CHX}$, has bacteriostatic action, altering the osmotic balance of the bacterial cell, promoting the release of low molecular weight molecules (potassium and phosphor). On the other hand, in high concentrations has the bactericidal action, promoting the cell death by cytolysis, causing an increase in membrane permeability and, as a result, release of major intracellular components, including potassium, so, the cell structure is altered causing the precipitation of the cytoplasmic proteins ${ }^{25}$. The efficacy of $\mathrm{CHX}$ is also related to its substantivity, which enables to remain bound to tissues having an antibacterial action of 8 to 12 hours, and it is possible to achieve the lowest effective dose required to inhibit bacterial plaque formation, even with a few administrations. Such substantivity is due to the ability of $\mathrm{CHX}$ to bind to mucins, which are proteins that form the salivary film. Studies performed by Carrilho et al. ${ }^{26}$ showed that with the increase of the concentrations of $\mathrm{CHX}$ applied in demineralized dentin an absorption takes place, where it can bind the collagen matrix and the underlying mineralized matrix, being the best way to inhibit the proteases that act on the collagen, prolonging the life of the restorations ${ }^{11,25,26}$.

Our results indicated that calcium hydroxide water did not affect shear bonding, but this have to be consider in self-etching systems. This may be because calcium hydroxide, even at low concentrations, has an affinity for the calcium ions present in dentin. Another reason may be the ability of the 10-methacryloyloxydecyl dihydrogen phosphate present in the CB formulation to bind to substrate calcium. The self-etching system have some functional monomers with only one or two chemical groups with connection to hydroxyapatite. In the case of self-etching adhesives, the adhesive interaction is reach through specifics functional monomers, like, 10-MDP, 4-MET and phenyl-P. However, the potential for chemical bonding alone is not efficient and the bonding formed must be stable in aqueous medium. Therefore, the chemical union promoted by 10-MDP is not only more effective, but also, more stable in water than the one promoted by 4-MET and phenyl- $\mathrm{P}^{27}$. So, the high index of clinical success of Clearfil SE Bond may be due to micromechanical union and the bonding promoted by 10-MDP. To the best of our knowledge, no studies to date have used calcium hydroxide water for this purpose, and the absence of data has prevented comparisons between studies and has to be consider that we only used in self-etching system.

The $70 \%$ ethyl ethanol is a substance widely used in clinical practice for disinfection. Actively applying $70 \%$ ethyl ethanol before dentin conditioning may have volatilized the ethanol, preventing subsequent solubilization of the acid monomers of the adhesive system, consequently preventing the decrease in shear bonding. Ethanol is widely used as a solvent in adhesive systems but is not present in the composition of $\mathrm{CB}$, which uses water as its solvent. The higher vapor pressure of ethanol compared with that of water allows better evaporation by air drying. Ethanol is com- 
monly used in conjunction with water as a co-solvent. In addition, water- ethanol mixtures are known to be azeotropic 28,29 . This characteristic allows the formation of hydrogen bonds between water and ethanol molecules, resulting in higher evaporation of water-ethanol mixtures compared with that of pure water, further causing increased removal of water from the adhesive material and increased surface dehydration ${ }^{30}$. Maciel et $\mathrm{al}^{31}$ have found that ethanol can harden demineralized collagen. This characteristic may explain why ethanol can keep interfibrillar spaces larger after solvent evaporation.

The use of $3 \%$ hydrogen peroxide decreased shear bonding loads, probably because of the presence of oxygen at the dentin/adhesive interface, resulting in the formation of an oxygen inhibition layer and consequent inhibition of polymerization ${ }^{32}$. Similarly, Ercan et al. ${ }^{5}$ observed that $3 \%$ hydrogen peroxide in a self-etching adhesive system yielded lower failure load values, but the loads produced using a conventional adhesive system did not decrease significantly.

In conclusion, chlorhexidine, calcium hydroxide water, and $70 \%$ ethyl ethanol did not significantly decrease shear bonding. Therefore, these agents can be used in combination with the self-etching adhesive system CB for restorative procedures. However, the use of $3 \%$ hydrogen peroxide is not indicated for this purpose.

\section{References}

1. Elkassas DW, Fawzi EM, Zohairy AE. The effect of cavity disinfectants on the micro-shear bond strength of dentin adhesives. Eur J Dent. 2014 Apr;8(2):184-90. doi: 10.4103/1305-7456.130596.

2. Dionysopoulos D. Effect of digluconate chlorhexidine on bond strength between dental adhesive systems and dentin: A systematic review. J Conserv Dent. 2016 Jan-Feb;19(1):11-6. doi: 10.4103/0972-0707.173185.

3. Say EC, Koray F, Tarim B, Soyman M, Gulmez T. In vitro effect of cavity disinfectants on the bond strength of dentin bonding systems. Quintessence Int. 2004 Jan;35(1):56-60.

4. Shinohara MS, Bedran-de-Castro AKB, Amaral CM, Pimenta LAF. The effect of sodium hypochlorite on microleakage of composite resin restorations using three adhesive systems. J Adhes Dent. 2004 Aug;6(2):123-7.

5. Ercan E, Erdemir A, Zorba OY, Eldeniz AU, Dalli M, Ínce B, Kalaycioglu B. Effect of different cavity disinfectants on shear bond strength of composite resin to dentin. J Adhes Dent. 2009 Oct;11(5):343-6.

6. Sharma V, Rampal P, Kumar S. Shear bond strength of composite resin to dentin after application of cavity disinfectants - SEM study. Contemp Clin Dent. 2011 Jul;2(3):155-9. doi: 10.4103/0976-237X.86438.

7. Tulunoglu $\mathrm{O}$, Ayhan $\mathrm{H}$, Olmez A, Bodur $\mathrm{H}$. The effect of cavity disinfectants on microleakage in dentin bonding systems. J Clin Pediatr Dent. 1998 Summer;22(4):299-305.

8. Soares CJ, Pereira CA, Pereira JC, Santana FR, do Prado CJ. Effect of chlorhexidine application on microtensile bond strength to dentin. Oper Dent. 2008 Mar-Apr;33(2):183-8. doi: 10.2341/07-69.

9. Pappas M, Burns DR, Moon PC, Coffey JP. Influence of a 3-step tooth disinfection procedure on dentin bond strength. J Prosthet Dent. 2005 Jun;93(6):545-50. 
10. Frassetto A, Breschi L, Turco G, Marchesi G, Lenarda RD, Tay FR, et al. Mechanisms of degradation of the hybrid layer in adhesive dentistry and therapeutic agents to improve bond durability- A literature review. Dent Mater. 2016 Feb;32(2):e41-53. doi: 10.1016/j.dental.2015.11.007.

11. Cha HS, Shin DH. Antibacterial capacity of cavity disinfectants against Streptococcus mutans and their effects on shear bond strength of a self-etch adhesive. Dent Mater J. 2016;35(1):147-52. doi: 10.4012/dmj.2015-175.

12. Hashimoto M, Ohno H, Sano H, Kaga M, Oguchi H. In vitro degradation of resin-dentin bonds analyzed by microtensile bond test, scanning and transmission electron microscopy. Biomaterials. 2003 Sep;24(21):3795-803.

13. Kermanshahi S, Santerre JP, Cvitkovitch DG, Finer Y. Biodegradation of resin-dentin interfaces increases bacterial microleakage. J Dent Res. 2010 Sep;89(9):996-1001. doi: $10.1177 / 0022034510372885$.

14. Spencer $P$, Wang $Y$. Adhesive phase separation at the dentin interface under wet bonding conditions. J Biomed Mater Res. 2002 Dec 5;62(3):447-56.

15. Ye Q, Park J, Topp E, Spencer P. Effect of photoinitiators on the in vitro performance of a dentin adhesive exposed to simulated oral environment. Dent Mater. 2009 Apr;25(4):452-8. doi: 10.1016/j.dental.2008.09.011.

16. Wang $Y$, Spencer P. Quantifying adhesive penetration in adhesive/dentin interface using confocal Raman microspectroscopy. J Biomed Mater Res. 2002 Jan;59(1):46-55.

17. Pashley DH, Tay FR, Yiu C, Hashimoto M, Breschi L, Carvalho RM. Collagen degradation by host-derived enzymes during aging. J Dent Res. 2004 Mar;83(3):216-21.

18. Mazzoni A, Pashley DH, Nishitani Y, Breschi L, Mannello F, Tjäderhane L, et al. Reactivation of inactivated endogenous proteolytic activities in phosphoric acid-etched dentine by etch-and-rinse adhesives. Biomaterials. 2006 Sep;27(25):4470-6.

19. Hashimoto M, Hirose N, Kitagawa H, Yamaguchi S, Imazato S. Improving the durability of resin-dentin bonds with na antibacterial monomer MDPB. Dent Mater J. 2018 Jul 29;37(4):620-627. doi: 10.4012/dmj.2017-209.

20. Scaffa PMC, Vidal CMP, Barros N, Gesteira TF, Carmona AK, Breschi L, et al. Chlorhexidine inhibits the activity of dental cysteine cathepsins. J Dent Res. 2012 Apr;91(4):420-5. doi: $10.1177 / 0022034511435329$.

21. Carrilho MR, Carvalho RM, de Goes MF, di Hipólito V, Geraldeli S, Tay FR, et al. Chlorhexidine preserves dentin bond in vitro. J Dent Res. 2007 Jan;86(1):90-4.

22. Ricci HA, Sanabe ME, de Souza Costa CA, Pashley DH, Hebling J. Chlorhexidine increases the longevity of in vivo resin dentin bonds. Eur J Oral Sci. 2010 Aug;118(4):411-6. doi: 10.1111/j.1600-0722.2010.00754.x.

23. Stanislavczuk R, Reis A, Loguercio AD. A 2 year in vitro evaluation of a chlorhexidine containing acid on the durability of resin dentin interfaces. J Dent. 2011 Jan;39(1):40-7. doi: 10.1016/j.jdent.2010.10.001.

24. Mohammed Hassan AM, Ali Goda A, Baroudi K. The effect of different disinfecting agents on bond strength of resin composites. Int J Dent. 2014;2014:231235. doi: 10.1155/2014/231235.

25. Di Hipólito V, Rodrigues FR, Piveta FB, Azevedo LC, Alonso RCB, Silikas N, et al. Effectiveness of self-adhesive luting cements in bonding to chlorhexidine-treated dentin. Dent Mater. 2012 May;28(5):495-501. doi: 10.1016/j.dental.2011.11.027.

26. Carrilho MR, Carvalho RM, Sousa EN, Nicolau J, Breschi L, Mazzoni A, et al. Substantivity of chlorhexidine to human dentin. Dent Mater. 2010 Aug;26(8):779-85 doi: 10.1016/j.dental.2010.04.002. 
27. Van Meerbeek B, Yoshihara K, Yoshida Y, Mine A, De Munk J, Van Landuyt KL. State of the art of self-etch adhesives. Dent Mater. 2011 Jan;27(1):17-28. doi: 10.1016/j.dental.2010.10.023.

28. Varoni E, Tarce M, Lodi G, Carrassi A. Chlorhexidine (CHX) in dentistry: state of the art. Minerva Stomatol. 2012 Sep;61(9):399-419.

29. Zhou J, Tan J, Yang X, Xu X, Li D, Chen L. MMP-inhibitory effect of chlorhexidine applied in a self-etching adhesive. J Adhes Dent. 2011 Apr;13(2):111-5. doi: 10.3290/j.jad.a18783.

30. Moszner N, Salz U, Zimmermann J. Chemical aspects of self-etching enamel-dentin adhesives: a systematic review. Dent Mater. 2005 Oct;21(10):895-910.

31. Maciel KT, Carvalho RM, Ringle RD, Preston CD, Russell CM, Pashley DH. The effects of acetone, ethanol, HEMA, air on the stiffness of human decalcified dentin matrix. J Den Res. 1996 Nov; $75(11): 1851-8$.

32. Morrison RT, Boyd RN. Organic chemistry. 3th ed. Boston: Allyn and Bacon; 1973. 